\title{
Professionalism in post-licensure nurses in developed countries
}

\author{
Karimah Alidina \\ Joseph Brant Memorial Hospital, Burlington, Ontario, Canada
}

Correspondence: Karimah Alidina, RN, MSN, CHPCN(C). Address: Joseph Brant Memorial Hospital, 1230 North Shore Boulevard, Burlington, ON, L7S 1W7, Canada. Email: kalidina@jbmh.com or Karimah.alidina@gmail.com.

Received: August 21, 2012

Accepted: September 20, 2012

Online Published: December 20, 2012

DOI : $10.5430 /$ jnep.v3n5p128

URL: http://dx.doi.org/10.5430/jnep.v3n5p128

\section{Abstract}

Professionalism is a multi-dimensional concept that provides nurses with opportunities to grow personally and professionally. Nurses demonstrating the attributes of professionalism impact positively on patient satisfaction and health outcomes. The objective of this article is to explore and analyze the phenomenon of nursing professionalism. The concept of professionalism will be explored by analyzing Miller's model entitled the "Wheel of Professionalism in Nursing". Factors determining professionalism in post-licensure nurses will be identified. The Registered Nurses Association of Ontario-Best Practice Guideline, "Professionalism in Nursing”, will be used to discuss strategies to foster professionalism in nurses. Relevance of professionalism in nursing and literature gaps will also be addressed.

\section{Key words}

Nursing professionalism, Professionalization, Factors affecting professionalism, Miller's model 'Wheel of Professionalism in Nursing', Concept analysis

\section{Introduction}

Professionalization is the process through which a person becomes socialized into a profession ${ }^{[1]}$. It is viewed as a process "by which a person acquires the knowledge, skills, and sense of occupational identity characteristic of a professional and involves the internalization of the values and norms of a professional group” ${ }^{[2]}$ (p.10). In nursing, the process of professional socialization begins during the foundational educational programs when nurses internalize the knowledge, skills, attitudes and professional standards and develop their own professional identity ${ }^{[1]}$. This internalization of professional socialization continues as the nurse practices in "the real world" (p. 198). Chitty believed that the "goal of professional socialization is the development of professionalism” ${ }^{[1]}$ (p. 198). Thus, it is generally understood that practising nurses integrate professionalization or professionalism into their nursing practice.

Several professional socialization models explain how nursing students socialize into their professional roles ${ }^{[3-7]}$. However, little is known about the process by which practising nurses continue to internalize, develop and sustain the characteristics attributed to the nursing profession into their practice. There is little empirical research to demonstrate the role of practicing nurses in maintaining and enhancing nursing professionalism. The lack of evidence which could provide nursing leaders with information regarding if and how practicing nurses maintain and enhance their professionalism upon entering the profession represents a gap in the body of nursing knowledge that requires an in-depth exploration. The 
purpose of this paper is to analyze the concept of nursing professionalism by investigating and describing the factors influencing professionalism in nurses and recommending strategies that may support the growth of nursing professionalism. Miller's model, the 'Wheel of Professionalism in Nursing' ${ }^{[8]}$ and the Registered Nurses Association of Ontario (RNAO)-Best Practice Guideline (BPG), 'Professionalism in Nursing, ${ }^{[9]}$ will be used to guide the exploration of this topic (see Figure 1).

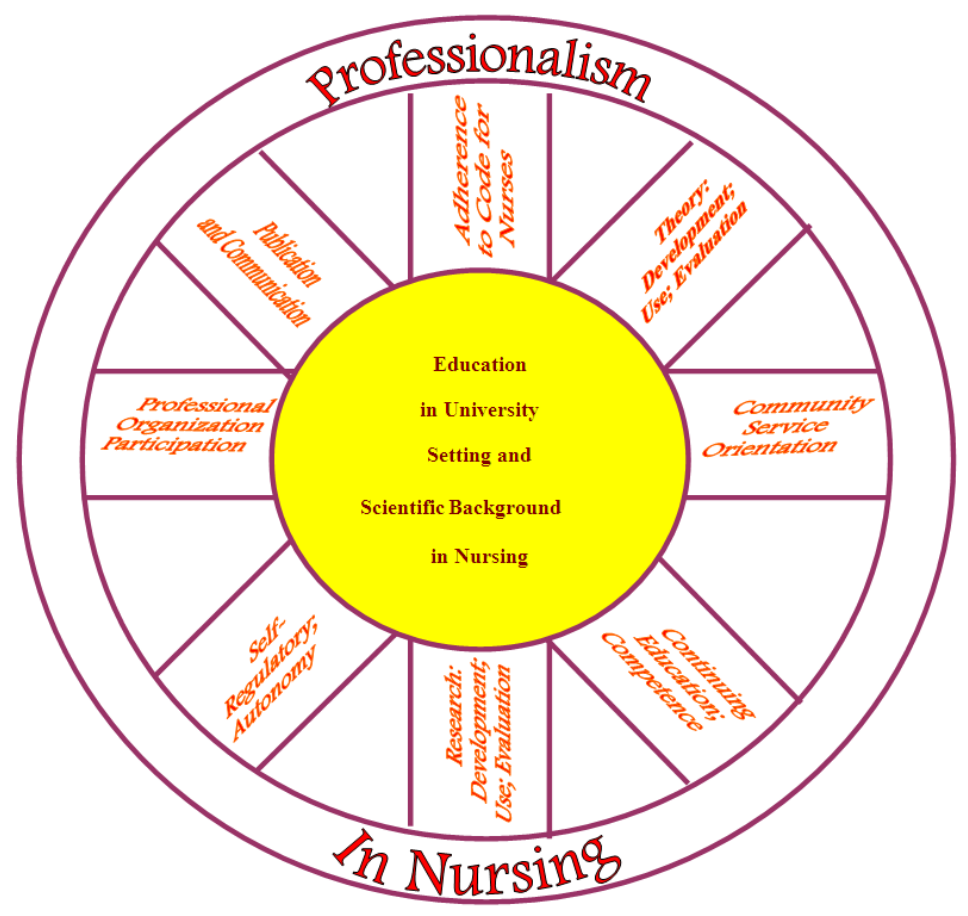

Figure 1. Wheel of Professionalism in Nursing ${ }^{[8]}$

\section{Literature search}

\subsection{Literature review process}

A comprehensive literature review was conducted using the electronic databases of MEDLINE, the Educational Resources Information Center (ERIC), CINAHL, PsychINFO, OVID, PubMed, Academic Search Elite, and WebSPIRS that includes literature from Social Science and Science and Technology. The main search terms used were 'nursing' and 'professionalism'. Other keywords used to locate the search were 'professional', 'professional identity', 'professional behaviour', 'professional socialization', 'profession', 'professionalization', 'professional autonomy', 'professional development' and 'professional knowledge'. These terms were combined with the term 'nursing' in order to retrieve empirical evidence on 'professionalism in post-licensure nurses'. To narrow the search, inclusion criteria was established to include all English language full-text articles. Boolean operators 'or' and 'and' were used to broaden and narrow the searches respectively. The search for unpublished studies (e.g. dissertations) was conducted using ProQuest. A search of grey literature was undertaken using Google and Google Scholar. Professional nursing websites were also explored for relevant references; in particular, the website, 'www.rnao.org' was accessed to examine current Best Practice Guideline (BPG) titled 'Professionalism in Nursing' ${ }^{\text {'9] }}$. Finally, reference lists of the retained articles were manually searched and sentinel literature was identified. 


\subsection{Understanding the meaning of profession and professionalism}

Profession is a Latin word that means "a calling requiring specialized knowledge and often long and intensive academic preparation" ${ }^{[10]}$. The term professionalism has been further described as "a vocation or form of employment that provides a needed service to society and possesses characteristics of expertise, autonomy, long academic preparation, commitment, and responsibility" ${ }^{[11]}$ (p. 34). The characteristics of professionalism, on the other hand, have been defined as the "conduct, goals or qualities that characterize or mark a profession or a professional person" ${ }^{[12]}$ (p.8). Adams, Miller and Beck reported that nursing professionalism requires nurses to demonstrate specific behaviours that illustrate the beliefs of the nursing profession ${ }^{[13]}$. These behaviours encompass the knowledge, attitudes and skills that represent the professional identity of nurses and their commitment to the profession ${ }^{[13,14]}$.

\subsection{Significance of professionalism in nursing}

Volp reported that the prime feature of nursing professionalism is the relationship between the nurse and the patient ${ }^{[15]}$. From this perspective, patients, families and communities expect nurses to demonstrate certain professional attributes while delivering nursing care. These attributes may include the demonstration of broad knowledge and skills, accountability, interpersonal skills and professional attitudes including effective communication, empathy and courtesy ${ }^{[16-18]}$. These characteristics are consistent with the attributes outlined in the Registered Nurses Association of Ontario-Best Practice Guideline, 'Professionalism in Nursing' ${ }^{\text {[9] }}$ and Miller's model the 'Wheel of Professionalism in Nursing, ${ }^{[8]}$.

Providing professional nursing care has been reported to result in improved patient satisfaction and positive health outcomes ${ }^{[15]}$. Increased levels of professionalism have also been associated with outcomes of improved nursing performance and personal autonomy ${ }^{[19]}$, ability to think critically ${ }^{[20]}$, ability to reflect on practice ${ }^{[21]}$, and empowerment ${ }^{[22]}$. In addition, nurses with a higher degree of professionalism have been reported to have enhanced levels of education and training; increased scholarship and involvement in research activities; and increased job satisfaction ${ }^{[15]}$. On the other hand, decreased levels of professionalism have been suggested to lead to negative outcomes including increased turnover and attrition and decreased productivity ${ }^{[23]}$.

\subsection{Conceptual model for professionalism in nursing}

In 1984, Barbara Kemp Miller developed a model entitled the 'Wheel of Professionalism in Nursing' to explore the concept of professionalism. This model (see Figure 1) was created in response to nurses' need to recognize attributes and behaviours necessary for the nursing professionalism ${ }^{[8,24,25]}$. This model is represented in the form of a wheel with essential characteristics as the hub and supporting behaviours represented as the spokes. The hub or center of the wheel represents two critical attributes including education in a university setting and a scientific background that is the basis for professionalism in nursing. The spokes depict attributes and characteristics that are inherent in the behaviours of a professional nurse. These attributes include, 'Adherence to Code for Nurses'; 'Community Service Orientation'; 'Professional Organization Participation'; 'Autonomy and Self-regulation'; 'Publication and Communication'; 'Development and use of Theory and Research'; and 'Continuing Education and Competence' ${ }^{[8]}$ (p. 19).

Formal education in a university setting is a means to acquire a body of knowledge through scientific research. Nurses are expected to possess professional attributes as a result of socialization during their professional education. Davis highlights the significance of educational preparation in socializing nursing students into their professional nursing role ${ }^{[26]}$. He views the socialization of nursing students as "the process by which the student passes from identification with a 'lay' to a 'professional' culture” ${ }^{[26]}$ (p. 116). Davis believes that the education programs and exposure to nursing academic faculty enables nursing students to internalize the skills, knowledge, and values associated with the professional nursing role.

Several researchers have debated over the entry level to nursing practice. Many researchers view the Baccalaureate (BSN) degree as a minimum educational requirement for professional nursing practice ${ }^{[27,28]}$. A higher educational level in nursing, specifically a minimum of BSN degree, is associated with a decrease in hospital mortality, length of stay, medication errors, and procedural violations ${ }^{[29,30]}$. Considering the benefits of higher education, many countries like 
Canada have established the BSN degree as a required standard for entry to practice. Canadian nurses are exploring means to advance their education by enrolling into various educational programs. It is evidenced by an increase in the enrolment of nurses from 8,013 to 10,074 in the BSN program between the period of 2005 and 2010. Even the admissions to Master's and Doctoral Programs have increased by $9 \%$ and $12 \%$ from the year 2005 to $2010^{\text {[31] }}$. Acquiring education with scientific background enables nurses to demonstrate knowledge, skills and values that are unique to the nursing profession.

Adherence to the Code For Nurses is an essential requisite for nursing professionalism as it defines the values and beliefs of the nursing profession ${ }^{[8]}$. The Code for Nurses is viewed as a valuable tool that allows nurses to practise ethically when dealing through ethical challenges arising in their nursing practice ${ }^{[32]}$. 'Community Service and Orientation to public' has also been fundamental to all professions including nursing. The Canadian Nurses Association (CNA) supports this Wheel through the Code of Ethics for Registered Nurses ${ }^{[32]}$ with expectation that nurses will demonstrate efforts to promote health and well-being of the public. Nurses motivated by altruism are committed to assist patients, families, groups, populations, and communities by providing services that can promote, restore and maintain health.

Professionalism also requires nurses to participate and promote professional organizations, which is another spoke of the Wheel. Various nursing associations (e.g. CNA) are dedicated to maintain self-regulation and control with a focus to protect the public. This regulation assures the public that they are receiving safe and ethical care from competent and qualified nurses. In Canada, all practising nurses are expected to participate in self-regulation by accepting responsibility to practise according to the professional standards and the code of ethics for Registered Nurses (RNs). This professional orientation is the key to autonomy in nurses which is another spoke of the Wheel. Autonomy or independence in nursing refers to freedom in making decisions and clinical judgement within their scope of practice ${ }^{[33]}$. Nurses demonstrate their autonomy by designing, implementing, and evaluating plans for patient care; developing and placing professional practice models in hospitals; and creating and pursuing advanced practice roles such as family nurse practitioner and clinical nurse specialist ${ }^{[34]}$.

Publication and communication is an additional spoke of the Wheel demonstrating the expectation that nurses can model professionalism by sharing, supporting, counselling and assisting other members of the health care team ${ }^{[8]}$. Nurses demonstrate this attribute through publication, by serving as a mentor or preceptor, by engaging in nursing organizations, or by acting as an advocate. A further functional element of professionalism includes theory and research whereby nurses assess, plan, implement and evaluate theory and research and integrate the best practices into their clinical practice. This spoke enables nurses to sustain an evidence-based practice environment at the bedside by maintaining competence through various continuing education opportunities ${ }^{[8]}$. Nurses, in this spoke, are expected to maintain and enhance their knowledge, skills, attitude and judgement to improve the quality of care provided to the patients, families and communities.

Miller's model, the 'Wheel of Professionalism in Nursing' is the most significant early work used to explore the phenomenon of nursing professionalism ${ }^{[8]}$. To test the empirical value of this model, Miller, Adams and Beck have developed a 'Behavioural Inventory for Professionalism in Nursing' that reflects the hub and spokes of the Wheel ${ }^{[25]}$. This inventory has been used by several researchers in their research practice and has developed good reliability ${ }^{[25]}$.

\subsection{Factors influencing professionalism in nursing}

Considering the 'Wheel of Professionalism in Nursing' model ${ }^{[8]}$, and the findings of a few descriptive studies, several researchers ${ }^{[13,35-38]}$ have outlined a few antecedents of professionalism. These antecedents include the levels of education, years of nursing experience, membership in professional organizations, community service and specialty certification. Malizia utilized a cross-sectional research design to determine the impact of the BSN degree on professional socialization of Returning RNs (RRNs) from three academic sites in Western New York ${ }^{[39]}$. The Nursing Activity Scale (NAS) developed by Schutzenhofer in 1992 was used to measure the degree of autonomy as a key professional behavior in nursing practice. The total scores of this scale ranges from 60 to 240 with higher scores indicative of greater autonomy. Data was collected from three categories of nurses including Associate Degree (AD)/Diploma nurses working in a hospital 
setting who chose not to return to school (31.5\%); RRNs from entering (87.5\%) and graduating class (56.8\%); and the graduates of Generic BSN program (28.7\%). The findings of this study revealed that RRNs from the entering and graduating class and Generic BSN graduates demonstrated higher level of professional autonomy while AD/Diploma nurses fell in the mid-range level. Graduating RRNs scored significantly higher on the NAS when compared to entering RRNs ( $P<0.1)$, AD/Diploma nurses $(P<.05)$, and Generic BSN nurses $(P<.05)$. The findings of this study may indicate that an increased level of education is positively associated with higher degree of professionalism ${ }^{\text {[39] }}$.

Wynd used a descriptive comparative/correlational design with a random sampling method to explore factors contributing to the levels of nursing professionalism ${ }^{[38]}$. Hall's Professionalism Inventory Scale ${ }^{[40]}$ was used to measure professionalism in 774 Registered Nurses licensed in the American state of Ohio. This inventory reflects essential dimensions of professionalism including the use of professional organizations, belief in public service, autonomy, belief in self-regulation and a sense of calling. Total scores on this inventory range between 25 and 125 with higher scores indicative of greater professionalism. The findings of Wynd's study reveal significant association between the overall professionalism scores and the higher educational degree in nursing $(p<.001)$, years of experience as an $\mathrm{RN}(p<.001)$, other certifications $(P<0.001)$ and membership in professional organizations $(P<.05)^{[38]}$. A stepwise multiple regression procedure was used to determine the strength of each variable in predicting total professionalism scores. Membership in professional organizations $\left(r^{2}=.048\right)$ and years of experience as an $\mathrm{RN}\left(r^{2}=.067\right)$ were found to be the most significant predictors of total scores of professionalism ( $p=<0.001$ ). The findings of this study may support the fact that nurses with increased years of experience in nursing practice, higher educational degrees, specialty certifications, and memberships in professional organizations may demonstrate increased professionalism in their practice settings ${ }^{\text {[38] }}$.

\subsection{Strategies to foster nursing professionalism}

Understanding the determinants of professionalism is an important step in promoting strategies that may support and enhance professional socialization in nurses. The 'Wheel of Professionalism in Nursing' model ${ }^{[8]}$ examines factors affecting nursing professionalism. Exploring the concepts outlined in this model may enable nurses to become more cognizant of professional behaviours. It may assist nurses in evaluating their own professionalism and may provide them the direction for professional growth ${ }^{[13,24,25]}$. In addition to using this model, nurses can also utilize the RNAO-BPG on 'Professionalism in Nursing' ${ }^{[9]}$ to examine the attributes that are fundamental to nursing professionalism. This BPG directs nurses on 'what to do or how to behave in professional situations' (p. 24) ${ }^{[9]}$. It recommends that nurses should model professionalism by: having a sound body of theoretical, practical and clinical knowledge; demonstrating high spirit of inquiry; exhibiting accountability; exercising autonomy; believing in advocacy; demonstrating innovation and visionary attitude; acknowledging collegiality and collaboration; and applying nursing ethics and values to clinical practice. Nurses can review this guideline and reflect on their own values and behaviours. They can then identify an area that they believe needs attention to enhance professionalism. Nurses may then consider the suggestions offered in this BPG to address their area of improvement ${ }^{[9]}$.

\subsection{Sound body of theoretical, practical and clinical knowledge}

The development and understanding of professional knowledge is important to the professional socialization process ${ }^{[9]}$. The application of knowledge and critical thinking skills are essential to establishing sound clinical judgement in nursing practice. The significance of education in enhancing professionalism is stressed by several researchers. Williams and MoGowan used a non-equivalent, pre-post test, control group design to determine the impact of professional development (PD) program on autonomy of nurses employed in a hospital in Western Australia ${ }^{[41]} .9$ clinical nurses received training on PD for a 10-week period through a planned 40 contact hour's session and 24 hours private study. A matched control group of clinical nurses $(\mathrm{n}=18)$ was selected from the hospital's nurse management database system. The 'Nursing Activity Scale' (NAS) was used to measure professional autonomy in nurses before and after the training program. The results of this study reveal that the NAS scores of nurses taking the PD course were significantly higher when compared to the nurses not taking the course $(P=0.0109)$, indicating the effectiveness of education in promoting autonomy in nurses ${ }^{[41]}$. Knowing that autonomy is one of the essential traits of professionalism, providing structured educational activities may assist in supporting and enhancing professionalism in nurses. Nurses can enhance their professional knowledge by 
accessing educational resources (e.g. library, conferences, and workshops) and by translating this knowledge to guide their clinical practice ${ }^{[9]}$.

\subsubsection{Spirit of inquiry}

Having a spirit of inquiry is considered to be the most distinguishing attribute of a professional nurse ${ }^{[9]}$. Nurses demonstrate this attribute by making observations, formulating questions, and gathering and interpreting data to enhance the provision of quality patient care ${ }^{[9]}$. It requires strengthening the knowledge base to make informed clinical judgments by thinking 'outside the box', or by reflecting critically and thinking creatively. Many studies have explored the significance of using reflective practice in promoting nursing professionalism ${ }^{[22-45]}$ and conclude that practising the act of reflection promotes self-insight and self-awareness in nurses that is essential to nursing professionalism. The College of Nurses of Ontario (CNO), through its Quality Assurance (QA) program, believes that life-long learning is essential to continuing competence. It engages nurses to measure their knowledge and application of professional standards by practising reflection and by developing and maintaining a learning plan ${ }^{[46, \text { a] }}$. Nurses participating in the QA program tend to reflect critically which may in turn assist nurses in transforming their perception of nursing professionalism and may enhance the quality of care provided to patients, families and communities ${ }^{[46, \text { a] }}$.

\subsubsection{Accountability}

Accountability in nursing is an integral part of professional practice. It refers to nurses' willingness to assume responsibility for their conduct ${ }^{[9]}$. Accountability is a key element of the CNO's professional standards that expects nurses to apply their knowledge and skills within their scope of practice to make decisions in the best interest of the patient ${ }^{[46, b]}$. Nurses are accountable to conduct self-assessment; identify areas requiring additional education, experience and/or supervision; and outline strategies to meet their learning needs ${ }^{[46, b]}$. Nurses can demonstrate accountability by becoming involved with their professional organizations; improving quality of care through evidence of best practices; self-reflection; and continuing education ${ }^{[9]}$.

\subsubsection{Autonomy}

Autonomy is viewed as the hallmark of nursing profession ${ }^{[9]}$. It refers to the ability of nurses to achieve a desirable outcome by making independent and informed decisions ${ }^{[47,48]}$. Autonomy in nurses is associated with job satisfaction ${ }^{[49]}$; increased patient safety and improved patient outcomes ${ }^{[50,51]}$. Stewart, Stansfield, and Tapp explored nurses' understanding of autonomy and identified the barriers and enablers to nursing autonomy using a qualitative hermeneutic approach ${ }^{[52]}$. 12 focus group interviews were conducted involving 43 nurses working in a large healthcare region in Southern Alberta, Canada. This approach engaged nurses in active exploration of what nursing autonomy means and how it could be enhanced in practice settings. The findings of this study reveal that nurses experienced autonomy when they were able to utilize their knowledge and skills to assess and meet patient's needs. Nurses felt less autonomous when their contributions to the patient care goals were unrecognized and unvalued. Continuing education, mentoring, and recognition were viewed as strategies to develop confidence and competence in enacting nursing autonomy ${ }^{[52]}$. The findings of this study are supported by RNAO-BPG 'Professionalism in Nursing' that suggests nurses to promote their autonomy by acting confidently within their scope of practice, improving decision making skills and taking formal and informal leadership roles ${ }^{[9]}$.

\subsubsection{Advocacy}

Advocacy is one of the fundamental values of professional nursing practice that requires nurses to empower patients to make informed choices by supporting their rights, values and beliefs ${ }^{[53-55]}$. Several researchers have examined the factors influencing nurses' role as patient advocates. Martin explored the perception of 20 RNs on 'advocacy' by asking them to describe an incident on advocacy arising from their clinical practice ${ }^{[56]}$. The reflective narratives from RNs revealed that maintaining a therapeutic nurse-patient relationship motivated nurses to act as patient advocates. However, the paternalistic attitudes of the healthcare providers along with the expectation for the patient to play a 'passive' role were viewed as barriers to advocacy ${ }^{[56]}$. These findings are supported by Mallik ${ }^{[55]}$ and Morse ${ }^{[57]}$ as they emphasize the need to develop a meaningful connection with patients to build foundation for advocacy. These researchers also view lack of 
support from healthcare team members and fear of reprisals as significant barriers to patient advocacy ${ }^{[55,57]}$. To overcome these barriers, nurses can involve themselves in shaping health policies that can improve the work environment and patient outcomes. Nurses can also recognize and respect the scope of practice of other healthcare professionals and identify and establish effective working relationships with key stakeholders to promote autonomy for clients. Furthermore, nurses can also contribute to policy development process by keeping themselves abreast of developments, participating in organizations, identifying key stakeholders and by communicating effectively ${ }^{[9]}$.

\subsubsection{Innovation and visionary}

Innovation and visionary refers to bringing in new ideas or imaginative insight to improve patient care and promote positive outcomes ${ }^{[9]}$. Innovative nursing has a positive impact on professional practice as it aims to improve job satisfaction and quality of care ${ }^{[58,59]}$. It enables nurses to think creatively and participate in quality improvement initiatives. Nurses can demonstrate their creativity by challenging the prevailing conditions and identifying opportunities that enhances nursing practice. Other strategies that may promote innovation and visionary attributes in nurses include recognizing opportunities to question and examine their practice; supporting curiosity, using reflective practice; and learning and embracing changes to improve the quality of health care ${ }^{[9]}$.

\subsubsection{Collegiality and collaboration}

Inter-professional collaboration is defined as "working together with one or more members of the healthcare team where each makes a unique contribution to achieving a common goal" ${ }^{[60]}$ (p. 18). Developing collaborative partnerships with other healthcare professionals and demonstrating collegiality are key attributes of professionalism ${ }^{[9]}$. They are viewed as significant predictors of positive patient outcomes; increased teamwork; job satisfaction; positive nurse-physician interactions; autonomy; and quality of care ${ }^{[61]}$. Nurses can promote collegiality and collaboration by having a clear understanding of their scope of practice as well as acknowledging and respecting the roles of other health care team members ${ }^{[9]}$. In addition, valuing preceptor programs and supporting mentorship opportunities may also assist nurses in demonstrating their collegiality ${ }^{[9,62]}$. These strategies may assist nurses to enhance collaborative relationships and teamwork, promote professional growth, boost sense of confidence, and support professional socialization in nurses.

\subsubsection{Ethics and values}

Providing safe, competent and ethical care is critical to nursing professionalism ${ }^{[9]}$. Esterhuizen highlights the significance of the nursing code of ethics in promoting accountability and professionalism in nurses ${ }^{[63]}$. Esterhuizen, however, claimed that nurses have little or no knowledge of the existing professional codes ${ }^{[63]}$. This claim is augmented by Miller, Adams and Beck ${ }^{[25]}$ who explored the levels of professionalism in RNs and revealed that only $40 \%$ of the RNs were aware of the American Nurses Association Code of Ethics. Furthermore, Adams and Miller, while exploring the levels of professionalism in Nurse Practitioners (NPs), revealed that 52\% of the NPs did not use an ethical framework in their nursing practice and only $12 \%$ of the NPs demonstrated their willingness to participate in ethics committee ${ }^{[24]}$. Knowing the fact that ethical dimension of nursing practice assists nurses in developing their professional identity ${ }^{[64,65]}$, and impacts the lives of patients, colleagues and society ${ }^{[66,67]}$, it becomes vital for nurses to apply the code of ethics in their nursing practice. To do so, nurses can reflect on their own values and beliefs and discuss its implications on the ethical dimensions of nursing practice. Nurses can also use various resources while making decisions and have critical incident de-briefing about practice issues related to ethics. More importantly, nurses can participate in regular meetings to address ethical and professional issues arising from clinical practice ${ }^{[9]}$.

\subsection{Literature gaps}

The concept of professionalism has been discussed in the healthcare literature for decades; however, many researchers agree that this phenomenon is under-researched. A few studies have explored the phenomenon of professionalism in nursing; however, most of these studies are descriptive in nature, thus, resulting in low-levels of evidence. The author realizes that a randomized controlled trial might not be the best way to explore the phenomenon of professionalism; however, various aspects of qualitative and quantitative designs must be considered to explore the efficacy of specific strategies fostering professionalism. Furthermore, researchers may also need to explore the influence of workplace 
settings on nursing professionalism. Recently, Baumann and Kolotylo have developed 'The Professionalism and Environmental Factors in the Workplace Questionnaire' (PEFWQ) ${ }^{\circledR}$ to examine professionalism and environmental attributes that may influence professionalism of nurses at their workplace ${ }^{[68]}$. This questionnaire was developed in response to the changes in the healthcare environment and resources that may make it challenging for nurses to maintain professionalism at all the times ${ }^{[68]}$. The authors (Baumann \& Kolotylo) caution readers that the intent of the PEFWQ ${ }^{\circledR}$ is not to measure an individual nurse's professionalism scores. Instead the analysis of the PEFWQ ${ }^{\circledR}$ result may provide "a starting point for collective discussion, planning and implementation of methods to support professionalism in practice and healthy work environments” ${ }^{[68]}$ (p. 2218). The development of PEFWQ ${ }^{\circledR}$ is particularly promising for nurses and nurse administrators to reflect, plan and implement strategies that may support nurses in maintaining and enhancing their levels of professionalism ${ }^{[68]}$.

\section{Conclusion}

Nurses need to demonstrate the attributes of professionalism in their daily practice as it impacts positively on patient satisfaction and health outcomes. It provides nurses with an opportunity to grow personally and professionally. This article explored the phenomenon of professionalism in nurses using Miller's model, 'Wheel of Professionalism in Nursing' ${ }^{[8]}$. It also explored the factors affecting nursing professionalism and outlined strategies to foster professionalism in nurses by using the RNAO-BPG, 'Professionalism in Nursing' ${ }^{[9]}$.

\section{Acknowledgements}

The author would like to acknowledge Registered Nurses of Ontario- Advanced Clinical Practice Fellowship Program and the guidance of her mentors that led to the development of this manuscript.

\section{References}

[1] Chitty KK. Professional Nursing: Concepts \& Challenges. 2001; 3rd ed. Philadelphia: W. B. Saunders.

[2] Jacox A. Professional socialization of nurses. In: The Nursing Profession: A View Through the Mist.1978; NL Chaska ed. McGraw-Hill New York, pp. 10-20.

[3] Cohen HA. The Nurse's Quest for a Professional Identity. 1981; Addison-Wesley, Menlo Park, California.

[4] Hinshaw AS. Socialization and resocialization of nurses for professional nursing practice. National League for Nursing. 1977; New York, pp. 1-15.

[5] Bandura A. Self-efficacy: Toward a unifying theory of behavioral change. Psychological Review. 1977; 84(2): $191-215$. PMid:847061 http://dx.doi.org/10.1037/0033-295X.84.2.191

[6] Benner P. From novice to expert. American Journal of Nursing. 1982; 82 (3): 402-407. PMid:6917683

[7] Throwe AN, Fought SG. Landmarks in the socialization process from RN to BSN. Nurse Educator. 1987; 12(6): 15-18. http://dx.doi.org/10.1097/00006223-198712060-00005

[8] Miller BK. A model for professionalism in nursing. Today’s OR Nurse. 1988; 19(9): 18-23.

[9] Registered Nurses Association of Ontario. Professionalism in Nursing. Healthy Work Environments Best Practice Guidelines. 2007; Toronto, Canada, Registered Nurses Association of Ontario.

[10] Profession. In Merriam-Webster’s Online Dictionary. Retrieved June 6, 2011. Available from: http://www.merriam-webster.com/dictionary/profession

[11] Huber D. Leadership and Nursing Care Management. 2000; Philadelphia, W. B. Saunders Company.

[12] Schwirian PM. Professionalization of Nursing: Current Issues and Trends. 1998; 3rd ed. Lippincott, Philadelphia, USA. PMid:10067640

[13] Adams D, Miller BK, Beck L. Professionalism behaviours of hospital nurse executives and middle managers in 10 Western States. Western Journal of Nursing Research. 1996; 18(1): 77-88. PMid:8686293 http://dx.doi.org/10.1177/019394599601800106

[14] Secrest JA, Norwood BR, Keatley VM. I was actually a nurse: The meaning of professionalism for Baccalaureate nursing students. Journal of Nursing Education. 2003; 42 (2): 77-82. PMid:12622335

[15] Volp K. Let’s talk nursing: Professionalism. The Queensland Nurse. 2006; November/December: 4-5. 
[16] Bendall-Lyon D, Powers T. The impact of structure and process attributes on satisfaction and behavioural intentions. Journal of Services Marketing. 2004; 18(2): 114-21. http://dx.doi.org/10.1108/08876040410528719

[17] Oermann MH, Templin T. Important attributes of quality health care: Consumer perspectives. Journal of Nursing Scholarship. 2000; Second Quarter: 167-72.

[18] Sivamalai S. Desired attributes of new graduate nurses as identified by the rural community. Rural and Remote Health [Internet]. 2008; 8: 938. Available from: http://www.rrh.org.au. PMid:18627217

[19] Schutzenhofer KK, Musser DB. Nurse characteristics and professional autonomy. Journal of Nursing Scholarship. 1994; 26(3): 201-5. http://dx.doi.org/10.1111/j.1547-5069.1994.tb00314.x

[20] Brooks KL, Shepherd, JM. Professionalism versus general critical thinking abilities of senior nursing students in four types of nursing curricula. Journal of Professional Nursing. 1992; 8(2): 87-95. http://dx.doi.org/10.1016/8755-7223(92)90068-A

[21] Wong FKY, Loke AY, Wong M, Tse H, Kan E, Kember D. An action research study into the development of nurses as reflective practitioners. Journal of Nursing Education. 1997; 36(10): 476-81. PMid:9413818

[22] Hausner JA. An examination of the relationship between psychological empowerment and professionalism in nursing. 2002; Dissertation UMI: 3073374. http://dx.doi.org/10.1016/S0147-9563(96)80117-8

[23] Boyle DK, Popkess-Vawter S, Taunton RL. Socialization of new graduate nurses in critical care. Heart and Lung. 1996; 25(2): 141-154.

[24] Adams D, Miller BK. Professionalism in nursing behaviours of Nurse Practitioners. Journal of Professional Nursing. 2001; 17(4): 203-10. PMid:11464342 http://dx.doi.org/10.1053/jpnu.2001.25913

[25] Miller BK, Adams V, Beck L. A behavioural inventory for professionalism in nursing. Journal of Professional Nursing. 1993; 9(5): 290-5. http://dx.doi.org/10.1016/8755-7223(93)90055-H

[26] Davis F. Professional socialization as subjective experience: The process of doctrinal conversion among student nurses. Chapter 6. in A Sociology of Medical Practice, edited by Cox C, Mead A. 1968; 116-131. Collier MacMillan. London.

[27] Hamner J, Bentley R. Learning from experience: Twelve years with 2nd degree BSN students. Nurse Educator. 2007; 32(3):126-9. PMid:17496507 http://dx.doi.org/10.1097/01.NNE.0000270223.30919.4c

[28] Kidder MM, Cornelius PB. Licensure is not synonymous with professionalism. It's time to stop the hypocrisy. Nurse Educator. 2006; 31(1): 15-9. PMid:16601600 http://dx.doi.org/10.1097/00006223-200601000-00005

[29] Estabrooks CA, Midozi WK, Cummings GG, Ricker KL, Giovannetti P. The impact of hospital nursing characteristics on 30-day mortality. Nursing Research. 2005; 54(2): 74-84. PMid:15778649 http://dx.doi.org/10.1097/00006199-200503000-00002

[30] Friese CR, Lake ET, Aiken LH, Silber, JH, Sochalski J. Hospital nurse practice environments and outcomes for surgical oncology patients. Health Services Research. 2008; 43(4):1145-63. PMid:18248404 http://dx.doi.org/10.1111/j.1475-6773.2007.00825.x

[31] Canadian Nurses Association. Registered Nurses Education in Canada Statistics: 2009-2010. Registered Nurse Workforce. 2012; Canadian Production: Potential New Supply.

[32] Canadian Nurses Association. Code of Ethics for Registered Nurses. 2008; Canadian Nurses Association, Ottawa, ON.

[33] Oermann M. Professional Nursing Practice. 1997; 1st ed. Stamford, CT: Appleton \& Lange.

[34] Ellis JR, Hartley CL. Nursing in Today’s World: Challenges, Issues and Trends. 1998; Philadelphia: Lippincott.

[35] Filiz-Hisar AK, Ozhan-Elbas N. The level of professionalism among nurses in Turkey. Journal of Nursing Scholarship. 2007; 39(4): 371-374. PMid:18021139 http://dx.doi.org/10.1111/j.1547-5069.2007.00195.x

[36] Hampton DL, Hampton GM. Professionalism and the nurse-midwife practitioner: An exploratory study. Journal of American Academy of Nurse Practitioners. 2000; 12(6): 218-25. http://dx.doi.org/10.1111/j.1745-7599.2000.tb00185.x

[37] Setterston L. Professionalism of Nurse Practitioners. Journal of the American Academy of Nurse Practitioners. 1991; 3(4): 145-51. http://dx.doi.org/10.1111/j.1745-7599.1991.tb01093.x

[38] Wynd CA. Current factors contributing to professionalism in nursing. Journal of Professional Nursing. 2003; $19(5): 251-61$. http://dx.doi.org/10.1016/S8755-7223(03)00104-2

[39] Malizia EE. Professional socialization of the Registered Nurse returning for a Baccalaureate degree. 2000; Dissertation International, UMI No. 9964396.

[40] Hall RH. Professionalization and bureaucratization. American Sociological Review. 1968; 33: 92-104. http://dx.doi.org/10.2307/2092242

[41] Williams S, MoGowan S. Professional autonomy. A pilot study to determine the effects of a professional development program on nurse's attitudes. Journal of Nursing Staff Development. 1995; 11(3): 150-5. PMid:7782873

[42] Durgahee T. Reflective practice: Nursing ethics through story telling. Nursing Ethics. 1997; 4: 135-46. PMid:9146268 http://dx.doi.org/10.1177/096973309700400205

[43] Gustafsson C, Fagerberg I. Reflection: The way to professional development? Journal of Clinical Nursing. 2004; 13: 271-9. PMid:15009329 http://dx.doi.org/10.1046/j.1365-2702.2003.00880.x 
[44] Pierson W. Reflection and nursing education. Journal of Advanced Nursing. 1998; 27:165-70. PMid:9515621 http://dx.doi.org/10.1046/j.1365-2648.1998.00509.x

[45] Woodward V. Achieving moral health care: The challenges of patient partiality. Nursing Ethics. 1999; 6: 390-8. PMid:10696186

[46] College of Nurses of Ontario. Quality Assurance: Fact Sheet Program Requirements. 2009; College of Nurses of Ontario, Toronto, ON. College of Nurses of Ontario. Professional standards: Revised 2002. 2009; College of Nurses of Ontario, Toronto, ON.

[47] Keenan J. A concept analysis of autonomy. Journal of Advanced Nursing. 1999; 29: 556-62. PMid:10210450 http://dx.doi.org/10.1046/j.1365-2648.1999.00948.x

[48] Wade GH. A model of the attitudinal component of professional nurse autonomy. Journal of Nursing Education. 2004; 43(3): 116-24. PMid:15072338

[49] Finn CP. Autonomy: An important component for nurses' job satisfaction. International Journal of Nursing Studies. 2001; 38: 349-57. http://dx.doi.org/10.1016/S0020-7489(00)00065-1

[50] Rafferty AM, Ball J, Aiken LH. Are teamwork and professional autonomy compatible and do they result in improved hospital care? Quality in Health Care. 2001; 10(2): 32-7.

[51] Weston MJ. Defining control over nursing practice and autonomy. The Journal of Nursing Administration. 2008; 38(9): 404-8. PMid:18791425 http://dx.doi.org/10.1097/01.NNA.0000323960.29544.e5

[52] Stewart J, Stansfield K, Tapp DM. Clinical nurses' understanding of autonomy: Accomplishing patient goals through interdependent practice. Journal of Nursing Administration. 2004; 34(10): 443-450. PMid:15577666 http://dx.doi.org/10.1097/00005110-200410000-00004

[53] Hamric AB. What is happening to advocacy? Nursing Outlook. 2000; 48: 103-104. PMid:10870015 http://dx.doi.org/10.1067/mno.2000.107644

[54] MacDonald H. Relational ethics and advocacy in nursing: Literature review. Journal of Advanced Nursing. 2007; 57(2): 119-26. PMid:17214748 http://dx.doi.org/10.1111/j.1365-2648.2006.04063.x

[55] Mallik M. Advocacy in nursing: Perceptions of practicing nurses. Journal of Clinical Nursing. 1997; 6: 303-13. PMid:9274232 http://dx.doi.org/10.1111/j.1365-2702.1997.tb00319.x

[56] Martin GW. Communication breakdown or ideal speech situation: The problem of nurse advocacy. Nursing Ethics. 1998; 5(2): 147-57. PMid:9616612

[57] Morse KJ. Patient advocacy: New skill or core competency? Nursing Critical Care. 2008; 3(3): 4.

[58] Arford PH, Zone-Smith L. Organizational commitment to professional practice models. Journal of Nursing Administration. 2005; 35(10): 467-72. PMid:16220060 http://dx.doi.org/10.1097/00005110-200510000-00008

[59] Hoffart N, Woods CQ. Elements of a nursing professional practice model. Journal of Professional Nursing. 1996; $12(6)$ : 354-64. http://dx.doi.org/10.1016/S8755-7223(96)80083-4

[60] College of Nurses of Ontario. Interprofessional Collaboration Among Health Colleges and Professions. 2008; College of Nurses of Ontario, Toronto, ON.

[61] Der V. Multidisciplinary rounds in our ICU: Improved collaboration and patient outcomes. American Association of Critical Care Nurses. 2009; 29(4): 83-4. PMid:2243329

[62] Cooper MD. Mentorship: The key to the future of professionalism in nursing. Journal of Perinatal and Neonatal Nursing. 1990; 4(3): 71-7.

[63] Esterhuizen P. Is the professional code still the cornerstone of clinical nursing practice? Journal of Advanced Nursing. 1996; 53(1): 104-13. PMid:16422701 http://dx.doi.org/10.1111/j.1365-2648.2006.03684.x

[64] Fagermoen MS. Professional identity: Values embedded in meaningful nursing practice. Journal of Advanced Nursing. 1997; 25: 434-41. PMid:9080267 http://dx.doi.org/10.1046/j.1365-2648.1997.1997025434.x

[65] Kelly B. Professional ethics as perceived by American nursing undergraduates. Journal of Advanced Nursing. 1992; $17:$ 10-5. PMid:1537981 http://dx.doi.org/10.1111/j.1365-2648.1992.tb01812.x

[66] Allmark P. Uncertainties in the teaching of ethics to students of nursing. Journal of Advanced Nursing. 1995; 22: 374-8. PMid:7593960 http://dx.doi.org/10.1046/j.1365-2648.1995.22020374.x

[67] Appleton C. The art of nursing: The experience of patients and nurses. Journal of Advanced Nursing. 1993; 18 : 892-99. PMid:8320383 http://dx.doi.org/10.1046/j.1365-2648.1993.18060892.x

[68] Baumann A, Kolotylo C. The professionalism and environmental factors in the workplace questionnaire ${ }^{\circledR}$ : Development and psychometric evaluation. Journal of Advanced Nursing, 2009; 65(10): 2216-28. http://dx.doi.org/10.1111/j.1365-2648.2009.05104.x 